\title{
Socioeconomic Dynamics of Neighborhoods and the Risk of Crime Victimization: A Multilevel Study of Improving, Declining, and Stable Areas in the Netherlands
}

\author{
JOHAN VAN WILSEM, Leiden University \\ KARIN WITTEBROOD, Social and Cultural Planning Office, \\ The Hague
}

NAN DIRK DE GRAAF, Radboud University, Nijmegen

\begin{abstract}
Changes in neighborhood status result primarily from the selective migration of income groups into and out of areas. These changes, in turn, are related to the chance of becoming the victim of a crime in a locality. Drawing on social disorganization theory, this study argues that victimization is more likely in disadvantaged neighborhoods as well as in neighborhoods where socioeconomic improvements are taking place. Gentrifying neighborhoods may suffer from social instability caused by the strong influx of new residents and from social heterogeneity, which is caused by the simultaneous presence of different income groups and, depending on local context, different ethnic groups. We test these hypotheses with Dutch victimization survey data among approximately 70,000 respondents, distributed across 2,500 neighborhoods within 500 municipalities in the Netherlands. The results show that, controlling for various individual, neighborhood, and city characteristics, intensive socioeconomic improvement of neighborhoods is related to higher victimization risk for theft, violence, and vandalism. In the Netherlands, high levels of residential instability in gentrifying areas are the mediating mechanism responsible for this relationship, while varying levels of ethnic and income heterogeneity are not. The results confirm that social disorganization is dependent not only upon the socioeconomic composition of neighborhoods, but also upon their socioeconomic dynamics.
\end{abstract}

A central finding in ecological crime studies is that disadvantaged neighborhoods are confronted with a relatively large amount of crime. Research from the United States (Bellair 1997; Lauritsen 2001; Sampson, Raudenbush, and Earls 1997) as well as other countries (Lee 2000; Sampson and Groves 1989; Wittebrood 2000) has found that the more concentrated low income groups are within an area, the higher the risk its inhabitants run of becoming the victim of a crime. According to social disorganization theory (Shaw and McKay 1942), the small amount of material and political resources held by the inhabitants of disadvantaged neighborhoods leads to a collective inability for internal organization. Indeed, in low status neighborhoods social contacts between community members are relatively few (Bellair 1997), participation in local organizations is rare (Sampson and Groves 1989), and trust in other people is low (Ross, Mirowsky, and Pribesh 2001). In such a context, collective social control is hard to realize, which, in turn, increases the attractiveness of the area as a place to commit crimes (Kornhauser 1978; Sampson et al. 1997; Van Wilsem, De Graaf, and Wittebrood

The authors would like to thank Jim Holstein and the anonymous reviewers for their valuable suggestions. This article was prepared under NWO Grant 490-24-142 from the Netherlands Organization for Scientific Research. Direct correspondence to: Johan van Wilsem, Leiden University, Department of Criminology, P.O. Box 9520, 2300 RA Leiden, The Netherlands. E-mail: J.A.van.Wilsem@LAW.leidenuniv.nl.

Social Problems, Vol. 53, Issue 2, pp. 226-247, ISSN 0037-7791, electronic ISSN 1533-8533.

(C) 2006 by Society for the Study of Social Problems, Inc. All rights reserved. Please direct all requests for permission to photocopy or reproduce article content through the University of California Press's Rights and Permissions website, at http://www. ucpress.edu/journals/rights.htm. 
2003). Furthermore, some scholars have argued that because members of disadvantaged neighborhoods have few connections with local government officials, they lack the ability to secure the external resources necessary for local crime control (Bursik and Grasmick 1993; Vélez 2001). Logically, it would therefore appear that efforts to reduce crime in disadvantaged neighborhoods should aim at increasing local socioeconomic status, for example, by renovation and renewal of the housing stock, which might lead to the inflow of more affluent inhabitants.

However, social disorganization theory predicts community cohesion to be low not only in disadvantaged neighborhoods, but also in areas characterized by strong social heterogeneity and instability (Bursik 1988; Kornhauser 1978; Shaw and McKay 1942). Social ties between community members decline with increasing social difference and decreasing average length of residency, which are due to strong migration flows into and out of a neighborhood. Scholars assume that this lack of social ties and resulting low levels of collective efficacy are among the prime determinants of local crime (Sampson et al. 1997). Since the socioeconomic upgrading of neighborhoods is often accompanied by increased social heterogeneity and instability (Atkinson 2000; Covington and Taylor 1989; Van Kempen and Van Weesep 1994), such processes of change may stimulate crime rather than decrease it. Also, urban geographers have pointed out the potential for conflict between old residents and new settlers in gentrifying neighborhoods (Atkinson 2000; Betancur 2002; Smith 1996). This also increases neighborhood disorganization, and ultimately, local crime.

Few studies have systematically addressed the relationship between gentrification and local crime victimization, yet it seems that crime is indeed more prominent in improving neighborhoods, compared to stable ones (Covington and Taylor 1989; Taylor and Covington 1988). Furthermore, the socioeconomic decline of neighborhoods is also associated with high local crime rates; because the concentration of low income groups stimulates social disorganization (Bursik and Webb 1982; Skogan 1990). This study evaluates how socioeconomic change relates to the risk of theft, violence, and vandalism in the neighborhood. Unlike previous studies on this topic, which were restricted to one city (e.g., Bursik and Webb 1982; Covington and Taylor 1989), the analyses in this study were performed on a countrywide scale for the Netherlands, including more than 2,500 neighborhoods for the period from 1994 to 1998.

Since gentrification of Dutch neighborhoods was more common in urban than in rural areas during this period, statistical controls were included for crime-inducing influences present in the wider spatial context (i.e., the city). The city context may determine victimization risk because the allocation of government resources for crime reduction differs across cities (Bursik and Grasmick 1993; Maume and Lee 2003; Skogan 1990). Also, the physical proximity of crime-inducing circumstances in nearby neighborhoods increases risk due to offender mobility and, possibly, because behavior that is prominent in surrounding neighborhoods is imitated by community members (Cohen and Tita 1999; Morenoff, Sampson, and Raudenbush 2001). By considering structural factors external to neighborhoods, this study expands on previous studies in which crime-inducing conditions in the wider context were taken into account (Heitgerd and Bursik 1987; Morenoff et al. 2001; Smith, Frazee, and Davison 2000).

\section{Theoretical Background}

Neighborhoods are confronted with a certain amount of social change over time, due to households settling in and moving out. Selectivity in these migration patterns is an important source of socioeconomic neighborhood change (Quillian 1999). To simplify, improving neighborhoods have high income household inflow, low income household outflow, or both, while these patterns are reversed in deteriorating neighborhoods. Developments in the extra-local housing market are the main driving force behind these movements (Organisation for Economic 
Co-operation and Development 1998). In areas where old housing stock is renovated and rental homes are replaced by owner-occupied dwellings, the supply of housing for higher income groups increases. Thus, gentrifying neighborhoods often experience a strong inflow of affluent households (Atkinson 2000; Butler and Robson 2001; Taylor and Covington 1988). Conversely, socioeconomic decline prevails in neighborhoods where investments in maintenance and improvement of the local housing stock are low. These areas have low competitiveness on the housing market because the local real estate offers little space and luxury (Skogan 1986). In such neighborhoods, the outflow of residents is selective, with affluent residents usually moving out first in search of better housing (South and Crowder 1997). Simultaneously, there are few incoming residents, and the new residents who do come are often disadvantaged households whose low incomes match the local housing prices, such as young people, ethnic minorities, and single parent households (Quillian 1999; Skogan 1986; Wilson 1987). Residents of deteriorating neighborhoods run a high risk of victimization due to the concentration of socioeconomic disadvantage around them and the low levels of social control that results from this (Bellair 1997; Sampson et al. 1997).

Traditionally, the social disorganization of neighborhoods has been assumed to be most likely to occur in disadvantaged and deteriorating areas (Kornhauser 1978; Shaw and McKay 1942; Skogan 1990). However, the consequences of neighborhood gentrification for risks of local victimization may not be unambiguously positive. On the one hand, improving neighborhoods become less disadvantaged due to the inflow of high income households. The accompanying increase in collective resources boosts the community's potential for internal organization and therefore decreases the risk of victimization (Butler and Robson 2001; McDonald 1986). On the other hand, the strong inflow of new affluent residents hampers the realization of social cohesion, because many neighbors are not acquainted yet or else have only known each other for a short time. Furthermore, social distance between residents is often more pronounced in gentrifying neighborhoods due to income differences between old and new residents (Atkinson 2000; Covington and Taylor 1989; DeGiovanni and Paulson 1984). Such heterogeneity generally undermines the formation of social contacts between residents and, consequentially, decreases the collective ability to achieve common goals, such as local safety (Sampson et al. 1997).

Levels of ethnic heterogeneity may also change with gentrification processes at work. However, as the opportunities for local heterogeneity depend on racial group sizes in the larger community, ethnic differences within neighborhoods may either increase or decrease through gentrification. In the United States, low income urban neighborhoods are predominantly non-white (Krivo and Peterson 2000; Quillian 1999), while high income settlers in gentrifying areas are mostly white (Lees 2000; Smith 1996). ${ }^{1}$ Thus, ethnic heterogeneity may increase with gentrification. In other contexts, however, such as the Netherlands and many other West European countries, ethnic minorities have smaller group sizes. Consequently, relatively few neighborhoods are composed of non-white majority populations. ${ }^{2}$ Although many non-white Dutch neighborhoods are relatively poor, the many disadvantaged areas are predominantly white. Under such circumstances, the migration of (mainly white) high income groups into gentrifying neighborhoods leads to decreases in ethnic heterogeneity.

Urban geographers have further argued that socioeconomic improvement in neighborhoods may involve conflict between old residents and newcomers, further discouraging the formation of social bonds between them. In The New Urban Frontier: Gentrification and the Revanchist City, Neil Smith (1996) sees gentrification as a class conflict pitting the affluent

1. Nevertheless, Bostic and Martin (2003) show that for some neighborhoods in Chicago, gentrification in the 1970s could be traced back to the inflow of black homeowners. Also see Lees (2000) for a similar example in Brooklyn.

2. In the Netherlands, neighborhoods with nonwhite majority populations are scarce and are found almost solely in the three largest cities: Amsterdam, The Hague, and Rotterdam. In 1998 (the year studied in this research), 28 Dutch neighborhoods had populations composed of 50 percent or greater non-Western residents (approximately 1 percent of all neighborhoods with available data). Of these, 25 were located in the three cities mentioned. 
against minority and low income households, and he sees the motivation for the competition as the struggle for ownership of the inner city space. Old residents hold new, affluent residents responsible for "buying out" the previous residents, people with whom older neighborhood members maintained social contact (Atkinson 2000; McDonald 1986). Indeed, Smith (1996), Jason Hackworth (2002), and John J. Betancur (2002) found that the gentrification of neighborhoods in New York, Chicago, and Philadelphia met with aggressive resistance from both displaced and remaining neighborhood members. In London, Rowland Atkinson (2000) found that longtime residents of gentrifying neighborhoods reacted to the inflow of affluent newcomers with coordinated campaigns to "mug a yuppie." Another reason for discontent among long term residents is that the attractiveness of the neighborhood decreases for them when local establishments cater to the material preferences of new residents (Atkinson 2000). Income inequality between community members may not only result in social disorganization but may also stimulate feelings of relative deprivation among the less affluent (Blau and Blau 1982; Taylor and Covington 1988). This induces tendencies toward criminal offending, although this behavior may be exercised elsewhere.

In sum, although gentrifying neighborhoods are not among the most disadvantaged, their inhabitants run a higher risk of victimization because the process of socioeconomic improvement brings with it social instability, heterogeneity and the potential for conflict. By arguing that positive socioeconomic neighborhood change is also accompanied by social disorganization, this study offers an explanation for variations in crime between seemingly welloff neighborhoods.

\section{The Micro and Macro-Level Contexts of Crime Victimization}

Social disorganization theory anticipates a positive relationship between neighborhood improvement and crime, but little attention has been devoted to testing this assumption empirically. As a consequence, little is also known about the duration of the improvement effect on local victimization, or whether safety problems are more severe during certain stages of the socioeconomic changing process. Ethnographic research on gentrification has pointed out the unintended side effect of increased crime (e.g., Atkinson 2000). Ralph B. Taylor and Jeanette Covington systematically examined crime problems of gentrified neighborhoods in Baltimore between 1970 and 1980 (Covington and Taylor 1989; Taylor and Covington 1988). Robert J. Bursik and Jim Webb (1982) addressed the relationship between socioeconomic community changes and shifts in delinquency over various 10-year periods among Chicago neighborhoods. However, while these studies offer interesting insights into the connection between socioeconomic dynamics and neighborhood crime, there are two notable limitations. First, their focuses on individual cities raise the question of the extent to which their results can be generalized. Second, the research by Bursik and Webb (1982) treats social disorganization as a motivational source of offending, with neighborhood structure affecting the offending frequency of its residents. As a consequence, it does not offer information about where offenders commit their crimes, only about where they live. Therefore, we cannot ascertain whether community changes lead to more crimes within these neighborhoods-or elsewhere.

This study expands on earlier work by analyzing the crime inducing impact of neighborhood dynamics on a countrywide scale in the Netherlands. Following recent criminological neighborhood research (Bellair 1997; Lee 2000; Sampson et al. 1997), we use an opportunityoriented approach to explain the connection between social disorganization and the victimization of residents within their neighborhoods. This approach considers neighborhood cohesion to be a macrolevel appearance of guardianship, one of the main elements of criminal opportunity (Bursik and Grasmick 1993; Lee 2000; Van Wilsem et al. 2003). As such, social disorganization reflects the lack of social control by community members, which reduces the chance that offenders will be caught. Consequently, the amount of disorganization deter- 
mines the extent to which neighborhoods are probable places for crime targets to be victimized. This approach tightly links social disorganization theory to the routine activities (lifestyle) model of victimization (Cohen and Felson 1979; Hindelang, Gottfredson, and Garofalo 1978). According to this reasoning, the individual's risk of victimization is partly determined by local neighborhood conditions, such as the amount of collective social control that is exercised (see also Sampson et al. 1997; Veléz 2001).

Following additional insights from routine activity theory (Cohen and Felson 1979), we acknowledge that the suitability of crime targets to offenders is not only shaped by neighborhood disorganization, but by individual target characteristics as well. In this respect, the opportunity model of victimization emphasizes the importance of targets' lifestyle traits that determine their personal guardianship (e.g., by individual crime prevention activities), and their exposure and attractiveness to offenders (Miethe, Stafford, and Long 1987; Mustaine and Tewksbury 1998). In our empirical analyses, we account for these notions in order to rule out the possibility that measurable neighborhood effects will be a result of ignoring compositional heterogeneity between ecological units.

Furthermore, we take into account that during the period between 1994 and 1998-this study's period of interest-neighborhood improvement in the Netherlands was most prominent in large cities. A sizable increase in the share of owner-occupied properties and a general improvement in housing quality in Amsterdam, Rotterdam, The Hague and Utrecht, the four largest Dutch cities, led to an increased inflow of affluent residents to these cities (Van der Wouden and De Bruijne 2001). In contrast, socioeconomic decline occurred most frequently in rural neighborhoods. Because neighborhood improvement has taken place mainly in the large cities, omitting city size from a model predicting victimization would probably lead to an overestimation of the effect of neighborhood improvement on crime. Central to this argument is the assumption that city context is relevant for predicting victimization, while it is simultaneously and systematically related to neighborhood improvement. Therefore, this study argues that it is vital to include city traits in the explanatory model of victimization.

City context is related to crime for two main reasons. First, large cities have high crime rates not only because they contain a disproportionately large number of disorganized neighborhoods, but also because the spatial proximity of that disorganization has an independent, added effect on crime. A possible reason for this is that offenders operating in certain places may, through their daily activities, routinely move about in areas nearby (Brantingham and Brantingham 1984; Smith et al. 2000). Also, community members might imitate dominant patterns of behavior from surrounding neighborhoods (Cohen and Tita 1999; Sampson, Morenoff, and Earls 1999). Jeffrey D. Morenoff, Robert J. Sampson, and Stephen W. Raudenbush (2001) offered support for these assumptions with their findings that, independent of the internal social structure, neighborhood levels of crime are higher the more that nearby neighborhoods suffer from crime (see also Smith et al. 2000). Second, apart from spatial dependency effects, hierarchical policy measures are another potential source of contextual influence that goes beyond neighborhood effects on crime. Following Robert J. Bursik and Harold Grasmick (1993), there are differences in the extent to which people can apply for external resources beneficial to the maintenance of local public safety. María B. Vélez (2001) found lower victimization risk in areas with high levels of public social control (i.e., many contacts between neighborhood inhabitants and local police or government officials). In this study, city-level public social control is included as an indicator of access to external resources, which is expected to reduce the chance of residents becoming the victim of a crime.

\section{Data and Methods}

To test the hypotheses, we combined victimization survey data with census data regarding the structural characteristics of neighborhoods (four-digit zip codes) and cities. The data 
for victimization and individual target characteristics were drawn from the Dutch Police Population Monitor (PPM; Dutch Ministry of Justice 1999). The PPM survey was conducted under the authority of the Dutch ministries of justice and domestic affairs. Within each of the Netherlands' 25 police regions, at least 1,000 interviews were collected, and in most regions substantially higher numbers were gathered. The overall sample consisted of 77,539 respondents age 15 years or older. ${ }^{3}$ Complete data were available for 69,819 respondents from 2,526 neighborhoods in 527 municipalities, covering some 65 percent of all Dutch neighborhoods and 98 percent of Dutch municipalities.

\section{Dependent Variables}

Respondents were asked whether they had been the victim of a crime during the past 12 months. Five different types of victimization were distinguished: burglary, car-related theft, violence, car vandalism, and other vandalism. For each of these, we constructed dichotomous variables to indicate whether the respondent had experienced this crime (1) or not (0). Respondents who reported a car theft or theft from a car were considered victims of carrelated theft. Respondents reporting threats, assault, or violent robbery were considered victims of violence. Because this part of the study focuses on the impact of local social conditions on victimization, incidents were selected that occurred within the respondent's neighborhood of residence. ${ }^{4}$ Of all victims of car-related theft, 59 percent reported at least one incident in their own neighborhood. For victims of violence, this amounted to 46 percent, while of all victims of car vandalism, 72 percent reported at least one neighborhood incident. For other vandalism, 82 percent of all victims experienced an incident in their own neighborhood.

\section{Independent Variables}

To control for compositional differences between neighborhoods, several individual target characteristics were included in the analyses. If these individual characteristics were related to victimization, and were differentially distributed across neighborhoods, they would offer an alternative explanation for neighborhood-level crime differences. Thus, by controlling for compositional differences, we were better able to test hypotheses about the link between social context and victimization (Sampson et al. 1997). Many studies (e.g., Hindelang et al. 1978) have found gender, age, marital status, and ethnicity to be correlates of victimization. These were thus introduced as control variables in the analyses. The measure for marital status shows whether the respondent was single (1) or married/cohabiting (0). Ethnic status was measured as a dichotomy, with respondents reporting to be Surinam, Turkish, Moroccan or Antillean receiving a score of 1 , and all others $0 .{ }^{5}$ Respondents' educational level indicates their attractiveness as a crime target because it is an indicator of socioeconomic status and, therefore, presumed possession of luxury goods. This variable has seven categories, ranging from "primary education" (1) to "university" (7).

Two variables reflect the respondent's housing conditions and provided additional measures of target attractiveness, with respect to theft. First, a distinction was made between home owners (1) and renters (0). Second, respondents were categorized as living in a detached house (1) or not (0). Furthermore, two lifestyle indicators measured the exposure to potential offenders and the level of personal guardianship over domestic property (Miethe et al. 1987). First, the respondent's main occupation was dichotomized into "working for a paid job" (1) versus "otherwise" (0). Second, respondents indicated the average number of hours their home was

3. Prior publications based on PPM data are scarce, but see Wittebrood and Junger (2002) and Tseloni et al. (2004).

4. No further instructions were given to respondents to define their neighborhood area.

5. A small number of other ethnic categories could not be disaggregated. These include both Western and nonWestern foreigners and are coded as 0 (not an ethnic minority). 
left unoccupied by one of six categories, ranging from "0 to 1 hour" (1) to "more than 40 hours" (6). ${ }^{6}$ Finally, for car-related crimes, the number of cars owned by the household was included as an indicator of the opportunity for car-related victimization the target presented.

At the neighborhood level, information was taken from Dutch census data (Main Indicators Four Digit Zip Codes 1999) published by the Dutch Central Bureau of Statistics (CBS), unless stated otherwise. First, a summary index of socioeconomic neighborhood disadvantage was computed, based on the results of a factor analysis including mean income per income recipient, percentage of income recipients with a low income (below the 40 percent line of the national income distribution) and percentage of income recipients between 15 and 64 years of age living on public benefit. In the index on socioeconomic disadvantage, these indicators were weighted by their factor loadings $(-0.85,0.95$, and 0.81 , respectively). Residential mobility was calculated as the ratio of residential moves into the neighborhood (inflow) to the total number of neighborhood inhabitants. This indicator was based on data from the Dutch postal services. For the area code available in the PPM data (four digit zip codes), measures on ethnic composition for Dutch neighborhoods are available only for the percentage of non-Western ethnic minorities. ${ }^{7}$ This is not equivalent to the traditional disorganization indicator of ethnic heterogeneity, which requires information on the relative size of each ethnic category. Still, our measure is likely to correlate highly with it, considering the relatively small percentage of ethnic minorities in many Dutch neighborhoods, which we noted earlier. Data availability restrictions also constrain the calculation of income heterogeneity to a rather rough measure. From two income groups (income recipients above the 80 percent line of the national income distribution and income recipients below the 40 percent line of the national distribution) the lowest prevalence rate was taken. Thus, the greater the relative size of the smallest income group, the more high and low income groups coexist within the same neighborhood. Finally, the percentage of youngsters age 15 to 24 was included to control for the proximity of potential offenders.

We used residual change scores to determine socioeconomic neighborhood dynamics between 1994 and 1998. These scores equal the residual of a regression analysis in which the initial levels of an indicator are used to predict levels at a later point in time (Bohrnstedt 1969). ${ }^{8}$ Thus, they give an indication of changes within the dynamics of the social system as a whole (in this case: the Netherlands). If an increase of a certain feature occurs in all neighborhoods, then this increase is "predicted" Therefore, residual change scores that diverge from zero imply deviations from the general pattern of change, and as such, they measure the direction of socioeconomic status redistribution within a neighborhood between two points in time. In this case, income levels in Dutch neighborhoods increased moderately, with a 10 percent change between 1994 and 1998. Thus, our residual change scores indicate how the development of neighborhood status differs from this general process of modest appreciation. Although residual change scores are often highly correlated to relative change scores $(r=0.90)$, they have the advantage of being independent of the feature's initial level. It should be emphasized that for the current analyses, this is important because regression estimates of neighborhood change on victimization may otherwise mask effects of a neighborhood's position of origin. ${ }^{9}$

6. No valid score on this variable was available for 2,983 respondents. They were therefore assigned a missing value. A dummy variable indicating whether respondents had a missing value for this question enabled us to determine whether this group differed from the assigned mean value in its relation to victimization.

7. These are people who have at least one parent born in a non-Western, developing country. This includes Turkey and countries in Africa, Latin America, and Asia, except for Japan and Indonesia (with this last country, the Netherlands had colonial relations in the past).

8. Previous crime studies that have used residual change scores are Bursik and Webb (1982), Covington and Taylor (1989), Schuerman and Kobrin (1986), and Taylor and Covington (1988).

9. The results of our regression models that include neighborhood status position of destination (1998) and residual neighborhood status change (between 1994 and 1998) were validated by additional analyses in which the first term was replaced by the mean status position of origin and destination. This way, we ascertained whether the effect of 
A summary index of socioeconomic neighborhood change was computed based on residual change scores on mean income per income recipient, the percentage of low income residents (with an income less than 40 percent of the national average), and the percentage of residents between 15 and 64 years of age living on public benefit. Again, each indicator in this index was weighted in proportion to its factor loadings $(-0.83,0.89$, and 0.54 , respectively). High values on this index indicate neighborhood decline, while low values point toward neighborhood improvement. Neighborhoods were categorized into five groups according to their value on the socioeconomic change index. If this value was at least two standard deviations higher than the mean, neighborhoods were considered to be experiencing strong decline. Neighborhoods with values at least two standard deviations lower than the mean were presumed to be experiencing strong improvement. If the change index value was between one and two standard deviations higher or lower than the mean, neighborhoods were categorized as undergoing moderate decline or experiencing moderate improvement, respectively. Neighborhoods that differed less than one standard deviation from the mean on the socioeconomic change index were considered to be stable. ${ }^{10}$

We controlled for three variables at the city level. First, the total number of inhabitants was included in the explanatory model. Values for this variable were subjected to natural log transformation to induce normal distribution. Second, because competing hypotheses can be formulated with regard to the city's mean income (per income recipient), it was introduced as a control variable. On the one hand, high levels of affluence may be an indication to offenders that the city accommodates many attractive targets, while on the other hand, it may offer local authorities a larger pool of resources to spend on law enforcement (Reiss 1986). Third, the public social control variable was represented by city-level performance of local police officials. This indicator was measured by subjecting respondent survey answers on this matter to ecometric analyses (Raudenbush and Sampson 1999). Four items in the PPM survey provided information for this purpose: (1) "the police [offer] protection around here," (2) "the police [react] to local problems," (3) "the police [try] hard in this neighborhood," and (4) "the police [handle] matters efficiently in this neighborhood" $(1=$ disagree, $2=$ do not agree or disagree, $3=$ agree). These questions offer insight into the availability of external resources for the benefit of neighborhood safety (see also Vélez 2001). By taking into account individual differences in propensity to agree with these items (see Appendix), the ecometric measure adjusts for compositional differences between ecological units, and therefore has improved comparative quality. Furthermore, unlike objective indicators of police performance, such as clearance rates, reporting rates and number of personnel, our ecometric measure does not suffer from serious registration inconsistencies or selectivity between areas (Baumer 2002; Novak et al. 2002; Warner 1997). As such, the inclusion of this measure fits in a recent tradition of sociological research that explores the possibilities to measure ecological constructs by survey answers of respondents, partly as a response to comparative problems associated with official ecological data (Kelly and Swindell 2002; Raudenbush and Sampson 1999; Reisig and Correia 1997).

The internal consistency of an ecometric measure not only depends upon the correlation between the items, the number of items, and the difficulty of the items (as is the case with an individual-level scale), but also upon the rater's agreement and the sample size within the

neighborhood change on victimization is dependent on the inclusion of neighborhood status position of origin. These additional analyses show that this is not the case for all types of victimization considered. The results are available upon request from the first author.

10. Only the neighborhoods characterized by strong negative residual change experienced mean income declines in absolute terms. Neighborhoods experiencing income increases well below the average increase of 10 percent were characterized as moderately declining, in terms of residual change. Income increases in neighborhoods experiencing moderate and strong positive residual change were well above average increases, with 16 percent and 22 percent, respectively. 
Table 1 - Descriptive Statistics of Dependent and Independent Variables

\begin{tabular}{|c|c|c|c|c|}
\hline & Mean & $S D$ & Minimum & Maximum \\
\hline \multicolumn{5}{|l|}{ Individual characteristics $(n=69,937)$} \\
\hline Victim burglary & 0.06 & 0.26 & 0 & 1 \\
\hline Victim car-related theft in neighborhood & 0.04 & 0.24 & 0 & 1 \\
\hline Victim violence in neighborhood & 0.02 & 0.15 & 0 & 1 \\
\hline Victim car vandalism in neighborhood & 0.13 & 0.33 & 0 & 1 \\
\hline Victim other vandalism in neighborhood & 0.07 & 0.25 & 0 & 1 \\
\hline Male & 0.44 & 0.50 & 0 & 1 \\
\hline Age & 45.12 & 16.71 & 15 & 98 \\
\hline Single & 0.20 & 0.40 & 0 & 1 \\
\hline Ethnic minority & 0.01 & 0.10 & 0 & 1 \\
\hline Educational level & 4.08 & 1.75 & 1 & 7 \\
\hline Working for a paid job & 0.58 & 0.49 & 0 & 1 \\
\hline Frequency nobody home & 3.85 & 1.51 & 1 & 6 \\
\hline Missing value frequency nobody home & 0.04 & 0.20 & 0 & 1 \\
\hline Home owner & 0.64 & 0.48 & 0 & 1 \\
\hline Detached house & 0.16 & 0.36 & 0 & 1 \\
\hline Number of cars & 1.14 & 0.72 & 0 & 7 \\
\hline \multicolumn{5}{|l|}{ Neighborhood characteristics $(n=2,526)$} \\
\hline \multicolumn{5}{|l|}{ Socioeconomic change, 1994-1998 } \\
\hline Strong decline & 0.02 & 0.12 & 0 & 1 \\
\hline Moderate decline & 0.10 & 0.31 & 0 & 1 \\
\hline Stability & 0.76 & 0.43 & 0 & 1 \\
\hline Moderate improvement & 0.08 & 0.28 & 0 & 1 \\
\hline Strong improvement & 0.03 & 0.18 & 0 & 1 \\
\hline Socioeconomic disadvantage 1998 & -0.03 & 0.97 & -6.36 & 3.40 \\
\hline Percentage ethnic minorities & 6.48 & 9.26 & 0 & 82 \\
\hline Percentage youngsters aged 15-24 & 11.79 & 2.86 & 5 & 40 \\
\hline Income heterogeneity & 20.14 & 6.30 & 5 & 38 \\
\hline Residential mobility & 3.98 & 2.27 & 0.82 & 50.9 \\
\hline \multicolumn{5}{|l|}{ City characteristics $(n=527)$} \\
\hline Total number of inhabitants (natural log) & 9.83 & 0.86 & 6.91 & 13.50 \\
\hline Mean income (in 1,000 Dutch guilders) & 32.86 & 2.76 & 27.8 & 47.2 \\
\hline Public social control & 0.00 & 0.08 & -0.34 & 0.45 \\
\hline
\end{tabular}

Source: Data from Dutch Police Population Monitor 1999 (Dutch Ministry of Justice 1999) and Dutch census data (Dutch Central Bureau of Statistics 1995, 1999).

ecological setting of interest (in this case, the city). The reliability of an ecometric scale is defined as $\Sigma\left(\tau_{00} /\left[\tau_{00}+\sigma^{2} / N_{j}\right]\right) / J$, with $\tau_{00}$ being the variance between cities, $\sigma^{2}$ the variance between individuals within the city, $N$ the sample size in the city, and $J$ the total number of cities (Sampson et al. 1999). The present measure for public social control has a reliability coefficient of 0.83 . Nevertheless, it should be noted that the intraclass correlation equals $0.033(0.016 /[0.016+0.471])$, which means that almost 97 percent of the scale variance is between individuals within cities. ${ }^{11}$ The appendix elucidates the construction of the ecometric measure for city-level public social control.

Table 1 offers a description of the variables used in this study.

11. However, Duncan and Raudenbush (1999) demonstrated that small contextual variance in individual-level measures does not rule out large contextual effects. 


\section{Analytic Strategy}

When using nested data (individuals within neighborhoods within cities) to test the hypotheses, it is important to take into account that measurement errors at the different levels are correlated. We, therefore, employed multilevel models, which estimate separate error terms at each analytical level (Snijders and Bosker 1999). Because the dependent variables are dichotomous (victim/not victim), logistic models are appropriate here. In hierarchical logistic models, the distribution of measurement errors at the individual level is presumed to be binomial. This parameter, therefore, has a fixed value of 1 . Additional analyses (not shown) indicated that this is a valid assumption for the current models. The errors at the neighborhood and city levels were presumed to follow a normal distribution (Snijders and Bosker 1999). In addition, the potential for multicollinearity was explored by examining variance inflation factor (VIF) scores and condition indices. Low values for VIF scores (below 4) and condition indices (below 9) in these analyses indicate that multicollinearity did not seriously affect parameter estimates (Belsley, Kuh, and Welsch 1980).

\section{Results}

Figure 1 and Table 2 describe several features of Dutch neighborhoods, distinguished by the kind of socioeconomic change they underwent between 1994 and 1998. Figure 1 displays two types of socioeconomic change for different types of neighborhoods: absolute change in the percentage of residents with a low income and a similar measure for high income residents. Again, low income refers to those under the 40 percent line of the national income distribution, while high income refers to those above the 80 percent line. ${ }^{12}$ These data do not refer to inflow or outflow of specific income groups, but rather to changes in their relative size within neighborhoods. In many of the neighborhoods that underwent strong improvements, the percentage of low income recipients decreased considerably, while the percentage high income recipients increased. However, there were several exceptions to this pattern. Also, among the other types of neighborhoods, there is differentiation in the specific socioeconomic changes they underwent.

From Table 2, several other differences are evident between improving, stable, and declining neighborhoods. First, residential mobility, in terms of inflow of new residents, is substantially higher among improving neighborhoods, especially among those that have undergone drastic change. Thus, these neighborhoods are dealing with high levels of social instability. With respect to income heterogeneity, lower levels are observed among declining and stable neighborhoods, compared to improving neighborhoods. The ethnic composition of an area also varies by type of socioeconomic dynamics. The relative number of non-Western immigrants is highest in declining neighborhoods. In improving neighborhoods, group sizes of non-Western ethnic populations are about average for 1998, and hardly different from the average size in stable neighborhoods. Additional analyses reveal that declining neighborhoods experienced the largest growth in non-Western population between 1994 and 1998 (more than 5 percentage points, with 3 percentage points being the overall growth rate). In improving neighborhoods however, initial levels of ethnic minorities were low, averaging approximately 5 percent, and ethnic growth rates from 1994 to 1998 were at the national average (approximately 3 percentage points).

Finally, socioeconomic dynamics are also unevenly distributed between cities of varying size. Improving neighborhoods are overrepresented among the largest cities in the Netherlands, while declining neighborhoods are most frequently located in small towns.

Table 3 depicts the results of logistic multilevel models for the prediction of victimization for burglary, car-related theft, violence, car vandalism, and other vandalism. For each

12. These specific measures are used due to their availability across a large number of Dutch neighborhoods. 


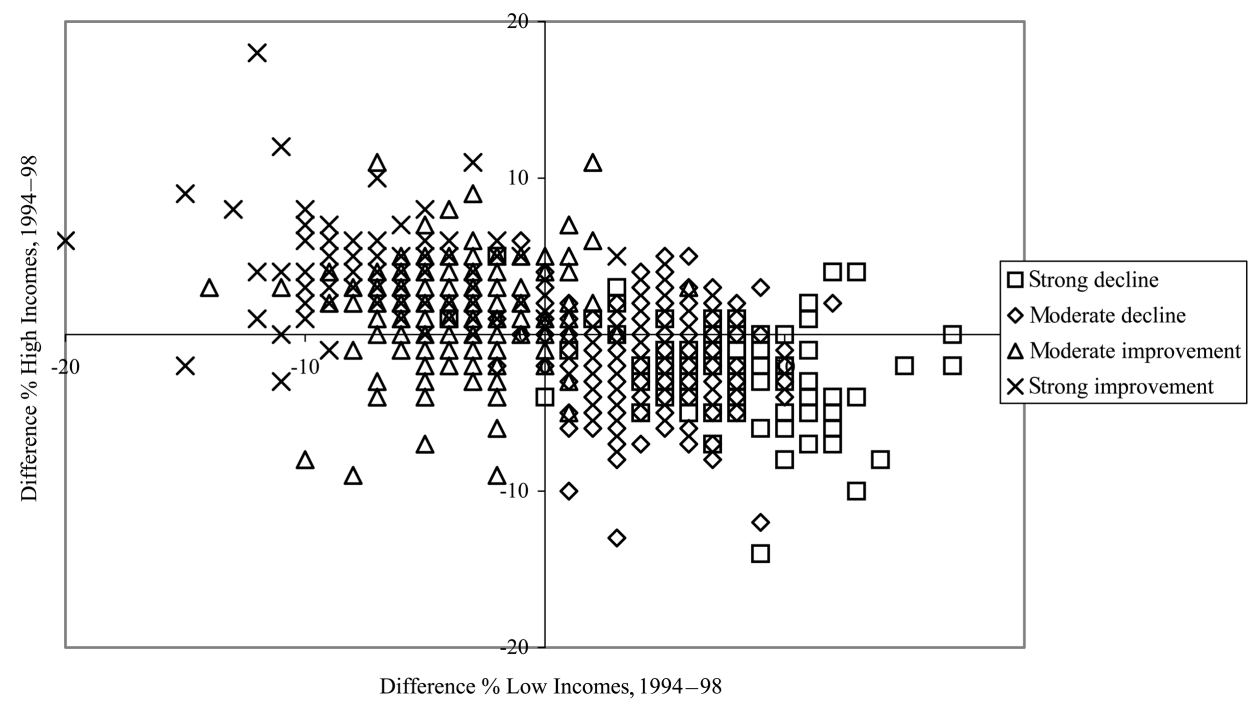

Figure 1 - Change in Percentage Low-and High-Income Recipients among Neighborhoods that Have Experienced Substantial Socioeconomic Dynamics

crime type, four separate models were estimated. In Model 1 , victimization risk is predicted using individual-level, neighborhood-level, and city-level predictors. Model 2 introduces neighborhood-level ethnic composition into the equation. In Model 3, we add income heterogeneity. Finally, Model 4 introduces residential mobility as an explanatory factor. These additive models allow us to evaluate changes in the effects of neighborhood change and victimization, in order to determine what the mediating mechanisms are. A short discussion of individual-level effects is offered first, after which we turn to neighborhood-level and citylevel effects.

At the individual level, many of our findings are consistent with opportunity-oriented theories of victimization (Hindelang et al. 1978; Miethe et al. 1987). For example, age is consistently related to each of the five types of crime, possibly because the daily routines of young people bring them into contact with other youngsters, who are overrepresented among offender populations (Hindelang et al. 1978). Working at a paid job and being part of a household that is frequently unoccupied increases the likelihood of becoming a victim of burglary, car-related theft, and car vandalism within the neighborhood. This is in line with the routine activity hypothesis that being away from home decreases people's ability to guard over their domestic property and therefore increases victimization risk (Hindelang et al. 1978). Furthermore, burglaries are committed more often in detached houses, while homeowners and people in detached houses experience less car-related theft and car vandalism than do renters and residents of other housing types. Although these categories score high on target attractiveness, the lower risks may be explained by the greater opportunity for indoor car storage and thus higher levels of guardianship.

At the neighborhood level, it appears that, for all five types of crime considered here, the risk of victimization is higher in places where a process of socioeconomic improvement has taken place over the past four years (Model 1). This offers consistent support for the association between gentrification and local crime victimization. Inhabitants of declining neighborhoods do not run higher risk of victimization, after controlling for higher levels of socioeconomic 
Table 2 - Characteristics of Neighborhoods, Distinguished by Type of Socioeconomic Change, 1994-1998

\begin{tabular}{|c|c|c|c|c|c|c|c|}
\hline & \multirow[b]{2}{*}{ Total } & \multicolumn{5}{|c|}{ Socioeconomic Neighborhood Change 1994-1998 } & \multirow[b]{2}{*}{$\begin{array}{l}\text { F-value } \\
(4,2521)\end{array}$} \\
\hline & & $\begin{array}{l}\text { Strong } \\
\text { Decline }\end{array}$ & $\begin{array}{l}\text { Moderate } \\
\text { Decline }\end{array}$ & Stability & $\begin{array}{l}\text { Moderate } \\
\text { Improvem't }\end{array}$ & $\begin{array}{c}\text { Strong } \\
\text { Improvem't }\end{array}$ & \\
\hline Total number & 2526 & 38 & 264 & 1926 & 214 & 84 & \\
\hline Residential mobility (mean) & 3.98 & 3.07 & 3.65 & 3.75 & 5.12 & 7.49 & $75.9^{*}$ \\
\hline Income heterogeneity (mean) & 20.1 & 15.6 & 16.6 & 20.2 & 23.3 & 23.2 & $54.5^{*}$ \\
\hline \multicolumn{8}{|l|}{ Percentage non-western } \\
\hline ethnic minorities (mean) & 6.48 & 8.84 & 8.32 & 6.17 & 6.47 & 6.71 & $\begin{array}{c}6.7^{*} \\
\chi^{2}(d f=8)\end{array}$ \\
\hline \multicolumn{8}{|l|}{ City size, \% } \\
\hline Less than 50,000 inhabitants & 63.3 & 89.5 & 64.0 & 65.8 & 48.1 & 28.6 & \\
\hline $\begin{array}{l}\text { 50,000-200,000 inhabitants } \\
\text { Four largest cities } \\
\text { (Amsterdam, Rotterdam, } \\
\text { The Hague, Utrecht) }\end{array}$ & 28.5 & 5.3 & 27.7 & 27.6 & 36.9 & 40.5 & $117.9 *$ \\
\hline
\end{tabular}

\footnotetext{
${ }^{a}$ Neighborhoods that experienced strong decline or strong improvement deviated at least two standard deviations from the mean on the residual change index, while neighborhoods undergoing moderate decline or improvement deviated between one and two standard deviations fro the index mean. The remaining neighborhoods are characterized as stable.

$* p<.01$.
}

disadvantage. Therefore, neighborhood decline is associated with victimization only insofar as these neighborhoods have a higher concentration of disadvantaged residents. In turn, concentration of socioeconomic disadvantage is consistently associated with a higher risk of theft, violence, and vandalism. Unexpectedly, residents of neighborhoods experiencing moderate decline have lower risks of victimization of car-related theft and non-car related vandalism. Furthermore, Model 1 shows that risks of victimization are higher with larger youth populations in the neighborhood.

Turning to the results of Model 2, we find the measure of ethnic composition to be related to victimization. Consistent with predictions from social disorganization theory, neighborhoods with larger shares of non-Western minorities are confronted with higher risks of victimization, for theft as well as for violence and vandalism. However, the relationship between socioeconomic change and victimization is not moderated by the inclusion of this variable. Thus, our finding that improving neighborhoods face higher victimization risk is not due to higher shares of ethnic minorities.

In Model 3, income heterogeneity was not found to be related to victimization at all, except for car vandalism. However, this effect was not in the expected direction. Thus, the introduction of neighborhood-level income heterogeneity hardly results in any substantial changes in the association between socioeconomic improvement and victimization. This also refutes the hypothesis that improving neighborhoods are confronted with more crime due to their higher levels of income heterogeneity.

Model 4 also controls for varying levels of residential mobility. This decreases the relationship between neighborhood improvement and victimization, turning to non-significance for both types of vandalism considered. A strong inflow of new residents increases victimization risk for all the types of crime examined here. In turn, such residential mobility is higher in improving neighborhoods compared to stable and declining neighborhoods (see Table 2). These findings consistently show the mediating role of social instability in the relationship between socioeconomic neighborhood improvement and local victimization risk. 
Table 3 - Unstandardized Coefficients from Multilevel Logistic Regression of Crime Victimization on Individual, Neighborhood, and City Characteristics

\begin{tabular}{|c|c|c|c|c|c|c|c|c|}
\hline & \multicolumn{4}{|c|}{ Burglary } & \multicolumn{4}{|c|}{ Violence } \\
\hline & 1 & 2 & 3 & 4 & 1 & 2 & 3 & 4 \\
\hline Intercept & $-3.15^{* *}$ & $-3.13^{* *}$ & $-3.13^{* *}$ & $-3.12^{* *}$ & $-4.08^{* *}$ & $-4.06^{* *}$ & $-4.06^{* *}$ & $-4.05^{* *}$ \\
\hline \multicolumn{9}{|l|}{ Individual $(n=69,937)$} \\
\hline Male $^{\mathrm{a}}$ & $.07 *$ & $.07 *$ & $.07 *$ & $.07 *$ & $.52 * *$ & $.52 * *$ & $.52^{* *}$ & $.52^{* *}$ \\
\hline Age & $-.01 * *$ & $-.01^{* *}$ & $-.01 * *$ & $-.01^{* *}$ & $-.03 * *$ & $-.03 * *$ & $-.03 * *$ & $-.03 * *$ \\
\hline Single $^{a}$ & .01 & .01 & .01 & .01 & $.14^{*}$ & $.14^{*}$ & $.15^{*}$ & $.14^{*}$ \\
\hline Ethnic minority ${ }^{\mathrm{a}}$ & -.12 & -.15 & -.15 & -.15 & -.38 & -.42 & -.42 & -.42 \\
\hline Educational level & $.06^{* *}$ & $.06^{* *}$ & $.06^{* *}$ & $.06^{* *}$ & $.06^{* *}$ & $.06^{* *}$ & $.06^{* *}$ & $.06^{* *}$ \\
\hline Working for paid labor & $.09 *$ & $.09 *$ & $.09 *$ & $.09 *$ & -.11 & -.12 & -.12 & -.12 \\
\hline Frequency nobody home & $.03 * *$ & $.03 *$ & $.03 *$ & $.03 *$ & -.03 & -.03 & -.03 & -.03 \\
\hline $\begin{array}{l}\text { Missing value frequency } \\
\text { nobody home }\end{array}$ & $-.07^{* *}$ & $-.07^{* *}$ & $-.07^{* *}$ & $-.07^{* *}$ & -.05 & -.05 & -.05 & -.05 \\
\hline Home owner & .06 & -.03 & -.03 & -.03 & $-.50 * *$ & $-.50^{* *}$ & $-.50^{* *}$ & $-.50 * *$ \\
\hline Detached house & $.47^{* *}$ & $.47^{* *}$ & $.47^{* *}$ & $.48^{* *}$ & -.14 & -.14 & -.14 & -.13 \\
\hline Number of cars owned & - & - & - & - & - & - & - & - \\
\hline \multicolumn{9}{|l|}{ Neighborhood $(n=2,526)$} \\
\hline \multicolumn{9}{|l|}{ Socioeconomic change 1994-1998 } \\
\hline Strong decline & .08 & .09 & .10 & .12 & .13 & .14 & .13 & .17 \\
\hline Moderate decline & -.09 & -.11 & -.10 & -.10 & .08 & .07 & .05 & .06 \\
\hline Stability (ref.) & - & - & - & - & - & - & - & - \\
\hline Moderate improvement & $.20^{* *}$ & $.20^{* *}$ & $.19 * *$ & $.16^{*}$ & .18 & .13 & .14 & .06 \\
\hline Strong improvement & $.24^{*}$ & $.26^{*}$ & $.24^{*}$ & .16 & $.38^{* *}$ & $.40^{* *}$ & $.42^{* *}$ & $.25^{* *}$ \\
\hline Socioeconomic disadvantage 1998 & $.13 * *$ & $.09 * *$ & .07 & .07 & $.18^{* *}$ & $.14^{* *}$ & $.19^{* *}$ & $.21^{* *}$ \\
\hline Percent youngsters & $.02 * *$ & $.02 * *$ & $.02 * *$ & $.02^{* *}$ & $.02 *$ & .02 & .02 & .01 \\
\hline $\begin{array}{r}\text { Percent non-Western } \\
\text { ethnic minorities }\end{array}$ & - & $.01^{* *}$ & $.01^{* *}$ & $.01^{* *}$ & - & $.01^{*}$ & $.01^{*}$ & $.01^{*}$ \\
\hline Income heterogeneity & - & - & -.01 & -.00 & - & - & .01 & .02 \\
\hline Residential mobility & - & - & - & $.03 * *$ & - & - & - & $.05^{* *}$ \\
\hline \multicolumn{9}{|l|}{ City $(n=527)$} \\
\hline $\begin{array}{l}\text { Total number of inhabitants } \\
\text { (natural log) }\end{array}$ & $.26^{* * *}$ & $.23^{* *}$ & $.23 * *$ & $.22^{* *}$ & $.25^{* *}$ & $.22 * *$ & $.22^{* *}$ & $.20^{* *}$ \\
\hline Mean income ${ }^{a}$ & $.07 * *$ & $.06^{* *}$ & $.06^{* *}$ & $.06^{* *}$ & $.04 * *$ & .03 & .03 & .03 \\
\hline Public social control & $-.46^{*}$ & $-.49 *$ & $-.50^{*}$ & $-.50^{*}$ & .06 & .03 & .03 & .02 \\
\hline \multicolumn{9}{|l|}{ Variance components } \\
\hline Between cities & .03 & .03 & .03 & .03 & .05 & .04 & .04 & .04 \\
\hline Between neighborhoods & .11 & .10 & .10 & .10 & .08 & .07 & .07 & .06 \\
\hline Binomial error & 1.00 & 1.00 & 1.00 & 1.00 & 1.00 & 1.00 & 1.00 & 1.00 \\
\hline
\end{tabular}

${ }^{\mathrm{a}}$ Two-tailed test.

$* p<.05 \quad * * p<.01$ (one-tailed).

At the city level, the findings shown in Table 3 indicate that victimization and city size are positively related, net of individual and neighborhood characteristics. The single exception to this is "other vandalism." These findings suggest that crime and urbanism are associated, not only because of compositional differences between large cities and small towns, but that they are also associated because city size has an independent crime inducing effect. Furthermore, the relationship between victimization and city-level mean income is significantly positive for three crime types (burglary, car-related theft, and car vandalism) and slightly negative for one crime type (other vandalism). Finally, public social control and victimization risk 


\begin{tabular}{|c|c|c|c|c|c|c|c|c|c|c|c|}
\hline \multicolumn{4}{|c|}{ Car-Related Theft } & \multicolumn{4}{|c|}{ Car Vandalism } & \multicolumn{4}{|c|}{ Other Vandalism } \\
\hline 1 & 2 & 3 & 4 & 1 & 2 & 3 & 4 & 1 & 2 & 3 & 4 \\
\hline$-4.00^{* *}$ & $-3.97 * *$ & $-3.97^{* *}$ & $-3.94 * *$ & $-2.12^{* *}$ & $-2.11^{* *}$ & $-2.11^{* *}$ & $-2.08^{* *}$ & $-2.77^{* *}$ & $-2.76^{\star *}$ & $-2.76^{* *}$ & $-2.75^{* *}$ \\
\hline .04 & .04 & .04 & .04 & .00 & .00 & .00 & .00 & -.04 & -.04 & -.04 & -.04 \\
\hline$-.01^{* *}$ & $-.01^{* *}$ & $-.01^{* *}$ & $-.01 * *$ & $-.01^{* *}$ & $-.01^{* *}$ & $-.01^{* *}$ & $-.01^{* *}$ & $-.01^{* *}$ & $-.01^{* *}$ & $-.01^{* *}$ & $-.01^{* *}$ \\
\hline$-.22^{* *}$ & $-.22^{* *}$ & $-.22^{* *}$ & $-.23 * *$ & $-.28^{* *}$ & $-.27^{* *}$ & $-.28^{* *}$ & $-.28^{* *}$ & -.08 & -.08 & -.08 & -.08 \\
\hline .26 & .19 & .19 & .19 & $-.29 * *$ & $-.31^{* *}$ & $-.31^{* *}$ & $-.30^{* *}$ & -.11 & -.15 & -.15 & -.15 \\
\hline $.02 *$ & .02 & .02 & .02 & $.04 * *$ & $.04^{* *}$ & $.04 * *$ & $.04^{* *}$ & $.12 * *$ & $.12^{* *}$ & $.12 * *$ & $.12^{* *}$ \\
\hline $.20 * *$ & $.19 * *$ & $.19^{* *}$ & $.19^{* *}$ & $.13^{* *}$ & $.12^{* *}$ & $.12^{* *}$ & $.12^{* *}$ & .01 & .01 & .01 & .01 \\
\hline $.04^{*}$ & $.05^{* *}$ & $.05^{* *}$ & $.04^{* *}$ & $.04^{* *}$ & $.04^{* *}$ & $.04^{* *}$ & $.04^{* *}$ & $.03 * *$ & $.03 * *$ & $.03 * *$ & $.03 * *$ \\
\hline-.11 & -.11 & -.11 & -.11 & -.11 & -.11 & -.11 & -.11 & $-.21^{*}$ & $-.21^{*}$ & $-.21^{*}$ & $-.21^{*}$ \\
\hline$-.14^{* *}$ & $-.13^{* *}$ & $-.13^{* *}$ & $-.13^{* *}$ & $-.18^{* *}$ & $-.18^{* *}$ & $-.18^{* *}$ & $-.18^{* *}$ & .02 & .02 & .02 & .03 \\
\hline$-.42^{* *}$ & $-.41^{* *}$ & $-.41^{* *}$ & $-.40^{* *}$ & $-.73 * *$ & $-.73 * *$ & $-.73 * *$ & $-.72^{* *}$ & -.03 & -.02 & -.02 & -.02 \\
\hline $.76^{* *}$ & $.76^{* *}$ & $.76^{* *}$ & $.76^{* *}$ & $.64^{* *}$ & $.64^{* *}$ & $.64^{* *}$ & $.64^{* *}$ & - & - & - & - \\
\hline .17 & .17 & .17 & .22 & -.25 & -.24 & -.23 & -.19 & .14 & .15 & .16 & .19 \\
\hline$-.32^{* *}$ & $-.35^{* *}$ & $-.35^{* *}$ & $-.32^{* *}$ & -.08 & -.09 & -.07 & -.06 & $-.19^{* *}$ & $-.19^{* *}$ & $-.19^{* *}$ & $-.19^{* *}$ \\
\hline- & - & - & - & - & - & - & - & - & - & - & - \\
\hline $.26^{* *}$ & $.27^{* *}$ & $.27^{* *}$ & $.17^{*}$ & $.16^{* *}$ & $.16^{* *}$ & $.15^{* *}$ & .09 & .02 & .02 & .02 & -.03 \\
\hline $.56^{* *}$ & $.58 * *$ & $.57 * *$ & $.35 * *$ & $.16^{*}$ & $.16^{*}$ & .12 & -.03 & $.19^{*}$ & $.20^{*}$ & $.20^{*}$ & .09 \\
\hline $.14^{* *}$ & .06 & .04 & .06 & $.10 * *$ & $.08^{* *}$ & .01 & .03 & .04 & .01 & .00 & .02 \\
\hline $.04^{* *}$ & $.03 * *$ & $.03 * *$ & $.03 * *$ & $.03 * *$ & $.03 * *$ & $.03 * *$ & $.03 * *$ & $.03 * *$ & $.03 * *$ & $.03 * *$ & $.03 * *$ \\
\hline - & $.01 * *$ & $.01^{* *}$ & $.01^{*}$ & - & $.00^{*}$ & .00 & .00 & - & $.01^{*}$ & $.01^{*}$ & $.01^{*}$ \\
\hline - & - & -.01 & .00 & - & - & $-.01^{* * a}$ & $-.01^{* a}$ & - & - & -.00 & .00 \\
\hline - & - & - & $.07^{* *}$ & - & - & - & $.05^{* *}$ & - & - & - & $.04^{* *}$ \\
\hline $.46^{* *}$ & $.41 * *$ & $.41 * *$ & $.38^{* *}$ & $.27 * *$ & $.25 * *$ & $.25^{* *}$ & $.23 * *$ & $.05 *$ & .02 & .02 & .01 \\
\hline $.09 * *$ & $.07 * *$ & $.07^{* *}$ & $.07^{* *}$ & $.06^{* *}$ & $.05^{* *}$ & $.06^{* *}$ & $.06^{* *}$ & -.02 & $-.03 *$ & $-.03 *$ & $-.03 *$ \\
\hline$-.87^{* *}$ & $-.91 * *$ & $-.92 * *$ & $-.93 * *$ & -.23 & -.24 & -.26 & -.25 & -.05 & -.08 & -.08 & -.08 \\
\hline .11 & .10 & .10 & .11 & .06 & .06 & .06 & .06 & .03 & .03 & .03 & .03 \\
\hline .14 & .13 & .12 & .10 & .08 & .08 & .08 & .07 & .06 & .06 & .06 & .05 \\
\hline 1.00 & 1.00 & 1.00 & 1.00 & 1.00 & 1.00 & 1.00 & 1.00 & 1.00 & 1.00 & 1.00 & 1.00 \\
\hline
\end{tabular}

are inversely related to burglary and car-related theft, but unrelated to neighborhood violence and to both types of vandalism. The analyses, therefore, suggest that the deterrent effects of social control exercised by police officials are restricted to theft victimization.

To illustrate in more detail how neighborhood-level socioeconomic composition and dynamics are related to victimization, the predicted risk of victimization was plotted as a function of these features (Figures 2, 3, and 4). The predicted victimization risks were derived from the regression results in Table 3 (Model 1) and held constant for values of the other predictors in the model. The figures show that victimization becomes more likely with higher 


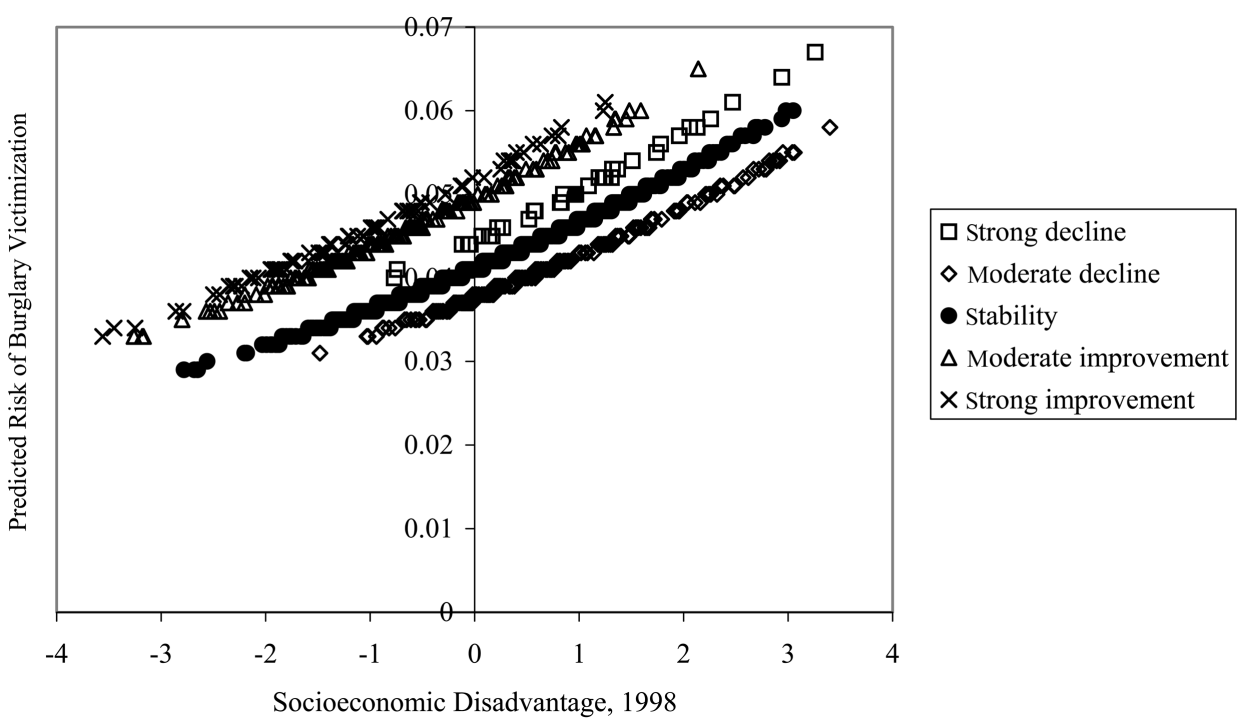

Figure 2 - Predicted Risk of Burglary Victimization, by Level of Neighborhood Disadvantage in 1998 and Socioeconomic Neighborhood Dynamics between 1994 and 1998

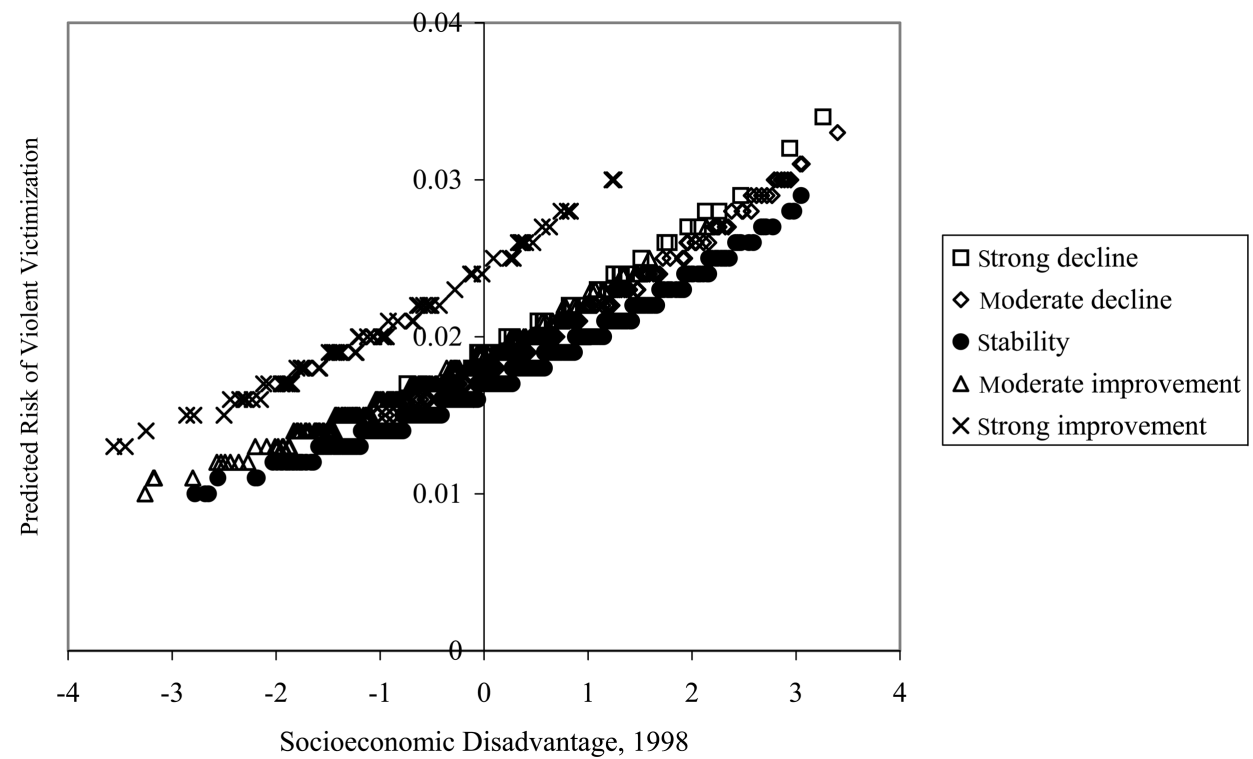

Figure 3 - Predicted Risk of Violent Victimization, by Level Of Neighborhood Disadvantage in 1998 and Socioeconomic Neighborhood Dynamics between 1994 and 1998 


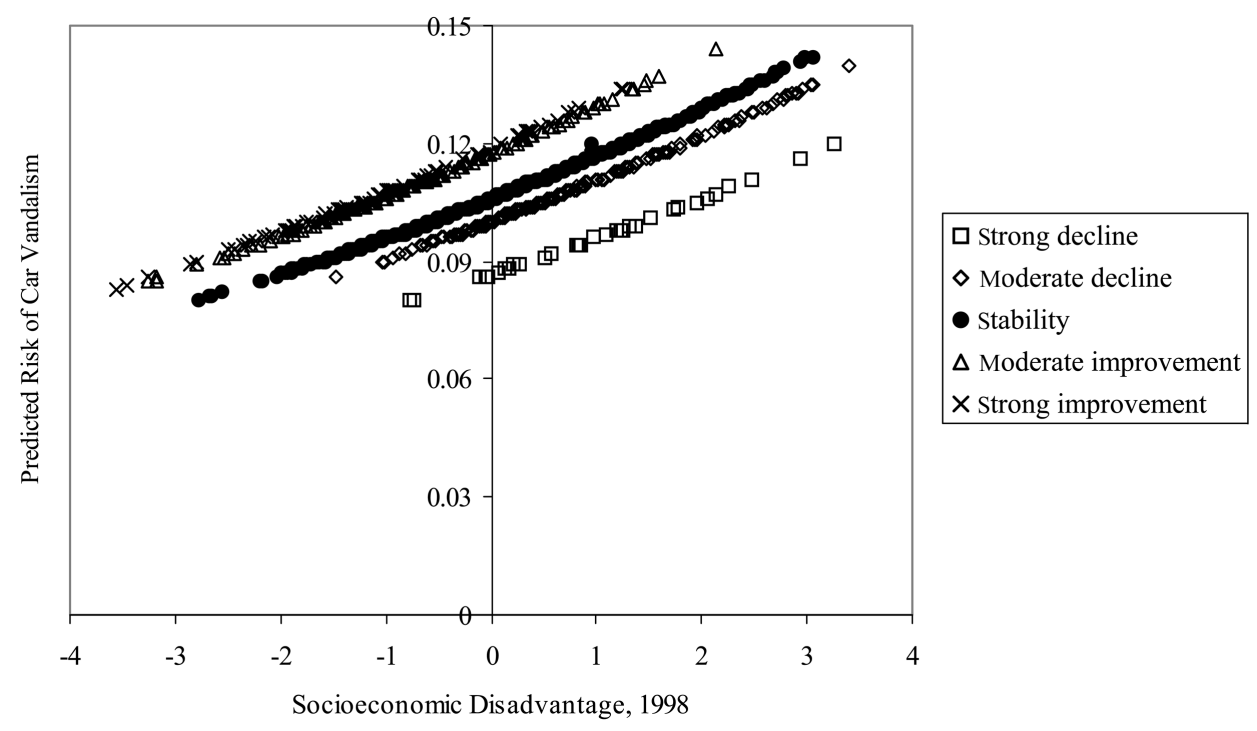

Figure 4 - Predicted Risk of Car Vandalism, by Level of Neighborhood Disadvantage in 1998 and Socioeconomic Neighborhood Dynamics between 1994 and 1998

levels of socioeconomic disadvantage. Also, declining neighborhoods are more likely to suffer from the concentration of socioeconomic disadvantage than are improving neighborhoods. However, high risks of victimization are not only found in disadvantaged neighborhoods; high risks are also found in non-disadvantaged neighborhoods that are undergoing strong socioeconomic improvement. If, despite this process, socioeconomic disadvantage remains above average, the chance of victimization is especially high, comparable to stable neighborhoods and to declining, yet more disadvantaged, neighborhoods. For instance, the highest predicted risks for burglary victimization (more than 5 percent) are found among inhabitants of improving neighborhoods that still have a moderately disadvantageous socioeconomic position, and among inhabitants of severely disadvantaged neighborhoods, which have declined the past four years, or remained stable. Similar conclusions can be drawn for victimization of violence (Figure 3) and car vandalism (Figure 4). These results show that victimization is not only more likely in disadvantaged neighborhoods, but that there are also pronounced crime differences between affluent neighborhoods, depending on their socioeconomic dynamics.

\section{Conclusions}

From this study of Dutch neighborhoods, we can conclude that the chance of becoming the victim of a crime is higher not only in disadvantaged neighborhoods, but also in neighborhoods that are undergoing strong socioeconomic improvement, at least over the four-year period covered by this study, from 1994 to 1998. The finding regarding the relationship between disadvantaged areas and victimization is consistent with many previous neighborhood studies on crime (e.g., Bellair 1997; Krivo and Peterson 2000; Sampson et al. 1997). The finding on improving neighborhoods sheds new light on the way in which a neighborhood's socioeconomic structure affects the risk of local victimization. Improving neighborhoods are not usually among the most disadvantaged, yet they do attract much crime. This was verified for five different types of victimization: burglary, car-related theft, violence, car vandalism, and other vandalism. 
Our analyses of Dutch neighborhoods suggest that socioeconomic dynamics is a process that is accompanied by additional social change, which has a crime-inducing potential. An important cause underlying neighborhood gentrification is a strong inflow of new (affluent) residents. According to social disorganization theory, such residential instability reduces the potential for collective social control, because unstable neighborhoods yield few social contacts between inhabitants. Indeed, our results show that victimization risk is higher in improving neighborhoods, as compared to socioeconomically stable neighborhoods, and that this relationship is largely mediated by varying degrees of residential instability. Other indicators of neighborhood disorganization, income heterogeneity and large shares of non-Western immigrants, did not mediate the relationship between socioeconomic improvement and local victimization. Though levels of income heterogeneity were higher in improving neighborhoodswith low income and high income groups often living in close proximity to each other-this variable did not affect victimization risk. The ethnic composition of the neighborhood did affect local victimization risk, with higher risk in areas with larger shares of non-Western immigrants, but improving and stable neighborhoods did not differ much from each other on this aspect.

Although these findings hold for the Netherlands, this does not mean that ethnic heterogeneity and within-neighborhood income differences should be dismissed for understanding the relationship between neighborhood improvement and victimization risk in other contexts as well. Gentrification of Dutch neighborhoods is certainly not driven solely by market forces, if one considers that "housing market controls and urban renewal policies have prevented even the most prestigious residential areas from becoming homogeneously high income districts" (Van Kempen and Van Weesep 1994). Conversely, Smith's (1996) and Betancur's (2002) accounts of gentrification in U.S. cities suggest that government support private sector efforts to allocate land for its most profitable use. In housing sectors where market forces are more pronounced than in the Netherlands, a relationship between gentrification and high victimization risk is anticipated as well, but possibly even more sharply due to higher expected levels of conflict between newcomers and remaining residents (Smith 1996), and higher (temporary) levels of income differences between neighborhood inhabitants, at least until substantial displacement of low income households has taken place. In addition, because ethnic heterogeneity is quite low in Dutch improving neighborhoods (and most other types of neighborhoods as well), it hardly contributed to an explanation of the association between gentrification and local victimization. It may, however, be a distinguishing feature in the context of urban neighborhood change in the United States (Betancur 2002).

In neighborhoods where improvements are taking place, decreases in victimization can be expected only after stabilization and, possibly, homogenization of the local community. It should also be noted that if low income groups relocate elsewhere, crime problems may be displaced rather than solved. On the other hand, if victimization risks in gentrifying areas remain high, affluent newcomers will probably have lower attachment to place because of the fear of crime and perceived incivilities (Brown, Brown, and Perkins 2004). Ultimately, they could choose to move out of the improved neighborhood in response to the high level of criminal activity (Morenoff and Sampson 1997). The neighborhood would then fall back into a process of socioeconomic decline, which, in turn, would keep local victimization rates high. It would therefore be interesting to investigate neighborhood developments over longer periods of time. This would allow us to examine whether local crime is an influence on the selectivity of migration patterns. Furthermore, on the methodological side, diagonal reference models (Sobel 1981) may prove to be a useful tool for further assessing the impact of neighborhood change on crime. In these models, local crime rates in changing neighborhoods are modeled as a weighted average of the crime rates in stable neighborhoods in the same position as their status of origin and stable neighborhoods in the same position as their status of destination. However, with current statistical programs, it is not yet possible to integrate diagonal reference models in multilevel analyses. 
Another direction for future investigation concerns the inclusion of additional, intermediary variables at the neighborhood level. The central assumption in this study was that neighborhoods vary in their capacity to exercise collective social control. Due to a lack of available data, it was impossible to test this assumption directly. Therefore, structural variables were used as factors that constrain social interaction between neighborhood residents, according to social disorganization theory. Several U.S. studies indicate that social contacts between neighborhood members, along with levels of collective efficacy, mediate the effects of these traditional disorganization indicators on crime (Bellair 1997; Sampson et al. 1997). Expanding on this, it would be interesting to explore whether the same holds true for the effects of neighborhood improvement on victimization. In addition, more direct empirical tests are needed to evaluate the possible link between gentrification and relative deprivation among the remaining low income households, which may stimulate local criminal activity, as suggested by Taylor and Covington (1988).

Finally, the results clearly show that victimization in one's own neighborhood is not only dependent upon individual and neighborhood characteristics, but also upon the city's social context. Individuals living in cities with a large number of inhabitants, high mean income, and low levels of public social control run a higher risk of becoming the victim of a crime, if the effects of individual and neighborhood characteristics are taken into account. This finding constitutes an addition to social disorganization theory, which has explained crime by focusing primarily on the internal characteristics of neighborhoods. These city-level effects support the assumption that social contexts beyond and external to neighborhoods are relevant for understanding local differences in crime rates. On one hand, the crime-reducing effect of public social control points toward a hierarchical effect through city policy (Bursik and Grasmick 1993). On the other hand, the effect of city size on victimization may reflect the crime-inducing potential of spatial proximity to social disorganization (Morenoff et al. 2001; Smith et al. 2000). More detailed studies on these two types of contextual effects external to neighborhoods provide intriguing paths for future inquiry.

\section{Appendix}

The city-level variance in public social control indicates the differences between cities in perceived police functioning in an ecometric measure, given item variance within individuals and individual variance within cities. The item-level model on public social control for individual $j$ within city $k$ on item $i$ is

$$
Y_{i j k}=\beta_{0 j k}+\Sigma \beta_{p}\left(X_{i j k}\right)+\varepsilon_{i j k}
$$

where $X_{i j k}$ is the item on public social control, and $\beta_{p}$ is the regression coefficient of the effect of this item on public social control, which indicates its 'difficulty': the lower $\beta_{p}$, the less often respondents agree with this item. $\beta_{0 j k}$ is the respondent's latent score, controlled for the difficulty of the items to which valid answers were given. On the individual level, the model is

$$
\beta_{0 j k}=\beta_{0 k}+\Sigma \beta_{q}\left(X_{j k}\right)+\mu_{0 j k^{\prime}}
$$

with $\beta_{0 k}$ being the city-specific score (which is divided into an overall average $\gamma_{00}$ and a cityspecific residual score $v_{k}$ ), $X_{j k}$ are individual characteristics for which the model is controlled (as will be explained in more detail below), $\beta_{q}$ is the regression weight assigned to these individual-level covariates, and $\mu_{0 j k}$ is the variance between individuals within city $k$. By holding constant for various individual characteristics associated with the perception of public social control, the city score on public social control $\left(v_{k}\right)$ is not distorted by compositional differences between cities.

In the ecometric analysis of city-level public social control, thirteen individual characteristics are adjusted for: gender, age, marital status (being single or not), belonging to an ethnic 
minority, educational level, working for paid labor, being a home owner, living in a detached house, and victimization of burglary, car-related theft, violence, car vandalism, or other vandalism. By controlling for the effect of victimization on public social control, the reciprocal effect between these two characteristics is taken into account: Victimization becomes more likely with low levels of public social control, while simultaneously, victims may perceive public social control to be lower compared to non-victims. Therefore, conservative estimates are offered for the effect of public social control on victimization.

Table A presents the results of the ecometric analysis. Respondents agree the least with the third item ("The police [try] hard in this neighborhood"), while the second item ("The police [react] to local problems") leads to most agreements. On the individual level, there are also differences in the propensity to perceive public social control. Males, older people, and singles more often report the presence of public social control than do females, youngsters, and married people, while educational level and home ownership are negatively related to public social control. Furthermore, victims of crime (especially violence) generally perceive lower levels of public social control than non-victims.

Table A • Multilevel Regression of Public Social Control on Items and Individual Characteristics

\begin{tabular}{lc}
\hline & $b$-coefficient \\
\hline Intercept & $2.016^{* *}$ \\
Item & $($ ref.) \\
The police offer protection around here & $.162^{* *}$ \\
The police react to local problems & $-.276^{* *}$ \\
The police try hard in this neighborhood & $-.261^{* *}$ \\
The police handle matters efficiently in this neighborhood & \\
Individual & $.055^{* *}$ \\
Male & $.004^{* *}$ \\
Age & $.005^{* *}$ \\
Single & -.048 \\
Ethnic minority & $-.021^{* *}$ \\
Educational level & -.003 \\
Working for paid labor & $-.020^{* *}$ \\
Home owner & .008 \\
Detached house & .000 \\
Victim burglary & $-.044^{* *}$ \\
Victim car-related theft & $-.124^{* *}$ \\
Victim violence & $-.100^{* *}$ \\
Victim car vandalism & $-.101^{* *}$ \\
Victim other vandalism & .016 \\
Variance components & .471 \\
Between cities & .814 \\
Between individuals & \\
Between items & \\
\hline
\end{tabular}

$* p<.05 \quad * * p<.01$ (two-tailed test). 


\section{References}

Atkinson, Rowland. 2000. “The Hidden Cost of Gentrification: Displacement in Central London." Journal of Housing and the Built Environment 15:307-26.

Baumer, Eric P. 2002. "Neighborhood Disadvantage and Police Notification to the Police." Criminology 40:579-616.

Bellair, Paul E. 1997. “Social Interaction and Community Crime: Examining the Importance of Neighbor Networks." Criminology 35:677-703.

Belsley, David A., Edwin Kuh, and Roy E. Welsch. 1980. Regression Diagnostics: Identifying Influential Data and Sources of Collinearity. New York: John Wiley \& Sons.

Betancur, John J. 2002. "The Politics of Gentrification. The Case of West Town in Chicago." Urban Affairs Review 37:780-814.

Blau, Judith R. and Peter M. Blau. 1982. “The Cost of Inequality: Metropolitan Structure and Violent Crime." American Sociological Review 47:114-29.

Bohrnstedt, George W. 1969. “Observations on the Measurement of Change." Pp. 113-33 in Sociological Methodology, edited by E. F. Borgatta. San Francisco: Jossey-Bass.

Bostic, Raphael W. and Richard W. Martin. 2003. "Black Home-Owners as a Gentrifying Force? Neighbourhood Dynamics in the Context of Minority Home-Ownership." Urban Studies 40:2427-49.

Brantingham, Paul J. and Patricia L. Brantingham. 1984. Patterns in Crime. New York: MacMillan.

Brown, Graham, Barbara B. Brown, and Douglas D. Perkins. 2004. “New Housing as Neighborhood Revitalization. Place Attachment and Confidence among Residents." Environment and Behavior 36:749-75.

Bursik, Robert J. 1988. "Social Disorganization and Theories of Crime and Delinquency." Criminology 26: 519-51.

Bursik, Robert J. and Harold Grasmick. 1993. Neighborhoods and Crime: The Dimensions of Effective Community Control. New York: Lexington Books.

Bursik, Robert J. and Jim Webb. 1982. "Community Change and Patterns of Delinquency." American Journal of Sociology 88:24-42.

Butler, Tim and Garry Robson. 2001. "Social Capital, Gentrification and Neighbourhood Change in London: A Comparison of Three South London Neighbourhoods." Urban Studies 38:2145-62.

Cohen, Jacqueline and George Tita. 1999. "Diffusion in Homicide: Exploring a General Method for Detecting Spatial Diffusion Processes." Journal of Quantitative Criminology 15:451-93.

Cohen, Lawrence E. and Marcus Felson. 1979. "Social Change and Crime Rate Trends: A Routine Activity Approach." American Sociological Review 44:588-608.

Covington, Jeanette and Ralph B. Taylor. 1989. "Gentrification and Crime: Robbery and Larceny Changes in Appreciating Baltimore Neighborhoods During the 1970s." Urban Affairs Quarterly 25: 142-72.

DeGiovanni, Frank and Nancy A. Paulson. 1984. "Household Diversity in Revitalizing Neighborhoods." Urban Affairs Quarterly 20:211-32.

Duncan, Greg J. and Stephen W. Raudenbush. 1999. "Assessing the Effects of Context in Studies of Child and Youth Development." Educational Psychologist 34:29-41.

Dutch Central Bureau of Statistics. 1995, 1999. Main Indicators Four Digit Zip Codes. Voorburg: Statistics Netherlands.

Dutch Ministry of Justice. 1999. Police Population Monitor. The Hague: Research and Documentation Centre of the Dutch Ministry of Justice.

Hackworth, Jason. 2002. "Postrecession Gentrification in New York City." Urban Affairs Review 37:815-43.

Heitgerd, Janet L. and Robert J. Bursik. 1987. “Extracommunity Dynamics and the Ecology of Delinquency." American Journal of Sociology 93:775-87.

Hindelang, Michael S., Michael Gottfredson, and James Garofalo. 1978. Victims of Personal Crime: An Empirical Foundation for a Theory of Personal Victimization. Cambridge, MA: Ballinger.

Kelly, Janet M. and David Swindell. 2002. "A Multiple-Indicator Approach to Municipal Service Evaluation: Correlating Performance Measurement and Citizen Satisfaction across Jurisdictions." Public Administration Review 62:610-21.

Kornhauser, Ruth. 1978. Social Sources of Delinquency. Chicago: University of Chicago Press.

Krivo, Lauren and Ruth D. Peterson. 2000. "The Structural Context of Homicide: Accounting for Racial Differences in Process." American Sociological Review 65:547-59.

Lauritsen, Janet. 2001. "The Social Ecology of Violent Victimization: Individual and Contextual Effects in the NCVS." Journal of Quantitative Criminology 17:3-32. 
Lee, Matthew R. 2000. “Community Cohesion and Violent Predatory Victimization: A Theoretical Extension and Cross-National Test of Opportunity Theory." Social Forces 79:683-706.

Lees, Loretta. 2000. “A Reappraisal of Gentrification: Towards a 'Geography of Gentrification.'” Progress in Human Geography 24:389-408.

Maume, Michael O. and Matthew R. Lee. 2003. “Social Institutions and Violence: A Sub-National Test of Institutional-Anomie Theory." Criminology 41:1137-72.

McDonald, Scott. 1986. "Does Gentrification Affect Crime Rates?" Pp. 163-201 in Communities and Crime, edited by A. J. Reiss Jr. and M. Tonry. Chicago: University of Chicago Press.

Miethe, Terance D., Mark C. Stafford, and J. Scott Long. 1987. "Social Differentiation in Criminal Victimization: A Test of Routine Activities/Lifestyle Theories." American Sociological Review 52:184-94.

Morenoff, Jeffrey D. and Robert J. Sampson. 1997. "Violent Crime and the Spatial Dynamics of Neighborhood Transition: Chicago, 1970-1990." Social Forces 76:31-64.

Morenoff, Jeffrey D., Robert J. Sampson, and Stephen W. Raudenbush. 2001. "Neighborhood Inequality, Collective Efficacy, and the Spatial Dynamics of Urban Violence." Criminology 39:517-60.

Mustaine, Elisabeth E. and Richard Tewksbury. 1998. "Predicting Risks of Larceny Theft Victimization: A Routine Activity Analysis Using Refined Lifestyle Measures." Criminology 36:829-57.

Novak, Kenneth J., James Frank, Brad W. Smith, and Robin S. Engel. 2002. "Revisiting the Decision to Arrest: Comparing Beat and Community Officers." Crime and Delinquency 48:70-98.

Organisation for Economic Co-operation and Development (OECD). 1998. Integrating Distressed Urban Areas. Paris: OECD.

Quillian, Lincoln. 1999. "Migration Patterns and the Growth of High-Poverty Neighborhoods, 1970-1990." American Journal of Sociology 105:1-37.

Raudenbush, Stephen W. and Robert J. Sampson. 1999. “Ecometrics: Toward a Science of Assessing Ecological Settings with Application to the Systematic Social Observation of Neighborhoods." Sociological Methodology 29:1-41.

Reisig, Michael D. and Mark E. Correia. 1997. "Public Evaluations of Police Performance: An Analysis across Three Levels of Policing." Policing 20:31 1-25.

Reiss, Albert J., Jr. 1986. "Why are Communities Important in Understanding Crime?" Pp. 1-34 in Communities and Crime, edited by A. J. Reiss Jr. and M. Tonry. Chicago: University of Chicago Press.

Ross, Catherine E., John Mirowsky, and Shana Pribesh. 2001. "Powerlessness and the Amplification of Threat: Neighborhood Disadvantage, Disorder and Mistrust." American Sociological Review 66:568-91.

Sampson, Robert J. and W. Byron Groves. 1989. "Community Structure and Crime: Testing Social Disorganization Theory." American Journal of Sociology 94:774-802.

Sampson, Robert J., Jeffrey D. Morenoff, and Felton Earls. 1999. “Beyond Social Capital: Spatial Dynamics of Collective Efficacy for Children." American Sociological Review 64:633-60.

Sampson, Robert J., Stephen W. Raudenbush, and Felton Earls. 1997. "Neighborhoods and Violent Crime: A Multilevel Study of Collective Efficacy." Science 277:918-24.

Schuerman, Leo and Solomon Kobrin. 1986. "Community Careers in Crime." Pp. 67-100 in Communities and Crime, edited by A. J. Reiss Jr. and M. Tonry. Chicago: University of Chicago Press.

Shaw, Clifford R. and Henry D. McKay. 1942. Juvenile Delinquency in Urban Areas. Chicago: University of Chicago Press.

Skogan, Wesley. 1986. "Fear of Crime and Neighborhood Change." Pp. 203-30 in Communities and Crime, edited by A. J. Reiss Jr. and M. Tonry. Chicago: University of Chicago Press.

. 1990. Disorder and Decline: Crime and the Spiral of Decay in American Neighborhoods. New York: The Free Press.

Smith, Neil. 1996. The New Urban Frontier: Gentrification and the Revanchist City. London: Routledge.

Smith, William R., Sharon G. Frazee, and Elizabeth L. Davison. 2000 "Furthering the Integration of Routine Activity and Social Disorganization Theories: Small Units of Analysis and the Study of Street Robbery as a Diffusion Process." Criminology 38:489-524.

Snijders, Tom and Roel Bosker. 1999. Multilevel Analysis. An Introduction to Basic and Advanced Multilevel Modeling. London: Sage.

Sobel, Michael E. 1981. “Diagonal Mobility Models: A Substantively Motivated Class of Designs for the Analysis of Mobility Effects." American Sociological Review 46:893-906.

South, Scott and Kyle D. Crowder. 1997. "Escaping Distressed Neighborhoods: Individual, Community and Metropolitan Influences." American Journal of Sociology 102:1040-84.

Taylor, Ralph B. and Jeanette Covington. 1988. "Neighborhood Changes in Ecology and Violence." Criminology 26:553-89. 
Tseloni, Andromachi, Karin Wittebrood, Graham Farrell, and Ken Pease. 2004. “Burglary Victimization in England and Wales, the United States and the Netherlands. A Cross-National Test of Routine Activities and Lifestyle Theories." British Journal of Criminology 44:66-91.

Van der Wouden, Ries and Erica De Bruijne. 2001. De Stad in de Omtrek: Problemen en Perspectieven van de Vier Grootstedelijke Gebieden in de Randstad (The City and its Surroundings: Problems and Perspectives of the Four Large Urban Areas in the Randstad). The Hague: SCP.

Van Kempen, Ronald and Jan Van Weesep. 1994. "Gentrification and the Urban Poor: Urban Restructuring and the Housing Policy in Utrecht." Urban Studies 31:1043-56.

Van Wilsem, Johan, Nan Dirk De Graaf, and Karin Wittebrood. 2003. "Cross-National Differences in Victimization: Disentangling the Impact of Composition and Context." European Sociological Review 19:125-42.

Vélez, María B. 2001. “The Role of Public Social Control in Urban Neighborhoods: A Multilevel Analysis of Victimization Risk." Criminology 39:837-64.

Warner, Barbara D. 1997. "Community Characteristics and the Recording of Crime: Police Recording of Citizen Complaints of Burglary and Assault." Justice Quarterly 14:631-50.

Wilson, William J. 1987. The Truly Disadvantaged: The Inner City, The Under Class, and Public Policy. Chicago: University of Chicago Press.

Wittebrood, Karin. 2000. "Buurten en Geweldscriminaliteit: Een Multilevel Analyse" [Neighborhoods and Violent Crime: A Multilevel Analysis]. Mens $\theta$ Maatschappij 75:92-109.

Wittebrood, Karin and Marianne Junger. 2002. "Trends in Violent Crime: A Comparison between Police Statistics and Victimization Surveys." Social Indicators Research 59:153-73. 